\title{
Implementation of Collision Warning Algorithm Based on V2V Communications
}

\author{
Janeks Ahrems \\ Department of Transport Electronics and Telematics \\ Riga Technical University \\ Riga, Latvia \\ janek@elikss.lv
}

\begin{abstract}
- one of the major lines of development of intelligent transport systems is ensuring road traffic safety. Recent advances in the field of satellite navigation and wireless data transmission systems have enabled significant expansion of the capabilities of the existing driver assistance systems. The present article provides the pilot test results of the collision warning device for unsignaled road intersections.
\end{abstract}

Keywords—collision warning, V2V communication, intelligent transport system, traffic safety.

\section{INTRODUCTION}

Despite the constant modernization of the existing road infrastructure, the task of reducing the number of road accidents on problem-plagued road sections still remains quite urgent.

Of all the variety of road situations, passing of an unsignaled road intersection is the most dangerous one. Besides, poor weather conditions, bad visibility caused by roadside structures, and the driver's misjudgement of the distance to and the speed of an approaching vehicle may increase the risk of a road traffic accident.

Collision warning devices for intersections, which operate on the basis of the integrated use of satellite navigation and vehicle-to-vehicle communication, serve to complement the existing driver assistance systems.

\section{COLLISION WARNING ALGORITHMS}

Collision warning algorithms at an intersection are based on the analysis of information about the location, speed, course angle and other parameters of all road users. The main source of such information is the Global Positioning System GPS, data exchange is carried out by means of Vehicle-to-Vehicle (V2V) communication. The physical and datalink level of the aforesaid exchange is regulated by Standard IEEE802.11p. The message content and interval, as well as priority logic are regulated by the SAE J2735 standard [1].

Optionally, it may also include information about the road intersection configuration, which is either specified in the digital map or transmitted by the road infrastructure.
The algorithm, which is presented in [2], provide for the use of road infrastructure. The given algorithm require the use of a set of road traffic sensors, infrared transmitters and the V2I (Vehicle-to-Infrastructure) communication system. The collision warning algorithm, which is given in [3], is based on prediction of the minimal distance between the moving vehicles and it comparison with the preset safe distance without using the road infrastructure. The possibility of using vehicle-to-vehicle communication based on the $5.8 \mathrm{GHz}$ DSRC (Dedicated Short Range Communication) system for information exchange in urban driving situations is assessed in [4]. The results of testing the collision warning system based on the integrated GPS and INS information processing in real time are described in [5].

When performing the tests, which are described hereof, we used an algorithm based on a simplified geometric model of a car, taking into account the overall dimensions of the vehicle and a certain preset safety zone, which is determined by the minimum allowable distance between the vehicle and GPS accuracy [6].

The reference scenario suggests that two vehicles are moving towards an intersection by crossing courses and without stopping (Fig.1).

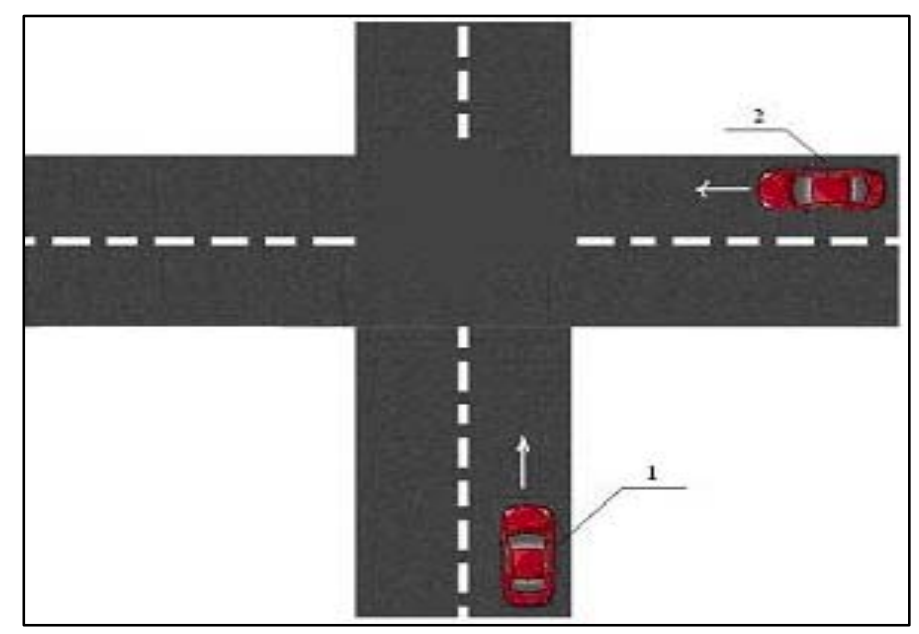

Fig. 1. Typical driving situation. 
A collision warning signal is formed by predicting the behaviors of the $S_{x}(t)$ and the $S_{y}(t)$ functions, which determine the imposition of the projections onto the $\mathrm{X}$ and the $\mathrm{Y}$ axes accordingly, at any one time. The $\mathrm{S}_{\mathrm{x}}(\mathrm{t})$ and the $\mathrm{S}_{\mathrm{y}}(\mathrm{t})$ functions are formed as follows (1):

$$
\left\{\begin{array}{l}
S_{X}(t)=[M A X(X)-M I N(X)]- \\
-[(M A X(X 1)-M I N(X 1))+(M A X(X 2)-M I N(X 2))] \\
S_{Y}(t)=[M A X(Y)-M I N(Y)]- \\
-[(M A X(Y 1)-M I N(Y 1))+(M A X(Y 2)-M I N(Y 2))],
\end{array},\right.
$$

where $\mathrm{X}$ and $\mathrm{Y}$ are the coordinates of the vehicles' limiting points as shown in Fig. 2.

The main criterion for safe passage of a road intersection is fulfilment of the condition (2) at any one time.

$$
S_{X}(t)>0 \text { OR } S_{Y}(t)>0,
$$

\section{VEHICLE EQUIPMENT CONFIGURATION}

Two motor cars were used for test purposes. Each of them was equipped with a system, whose structural scheme is given in Fig. 3.

A GPS receiver NAVILOCK EM-406A with an output in the NMEA 0183 format [7] provides the system with information about the current location, heading and speed of the car. The positional accuracy off the line is $5 \mathrm{~m}$, and that of the speed $-0.1 \mathrm{~m} / \mathrm{s}$.

A 5.8 GHz DSRC transceiver, based on a ML5805 microchip, enables the exchange of the obtained information with another transport vehicle. The ML5805 is a single chip fully integrated Frequency Shift Keyed (FSK) transceiver developed for a variety of applications operating in the $5.725 \mathrm{GHz}$ to $5.850 \mathrm{GHz}$ unlicensed ISM band.

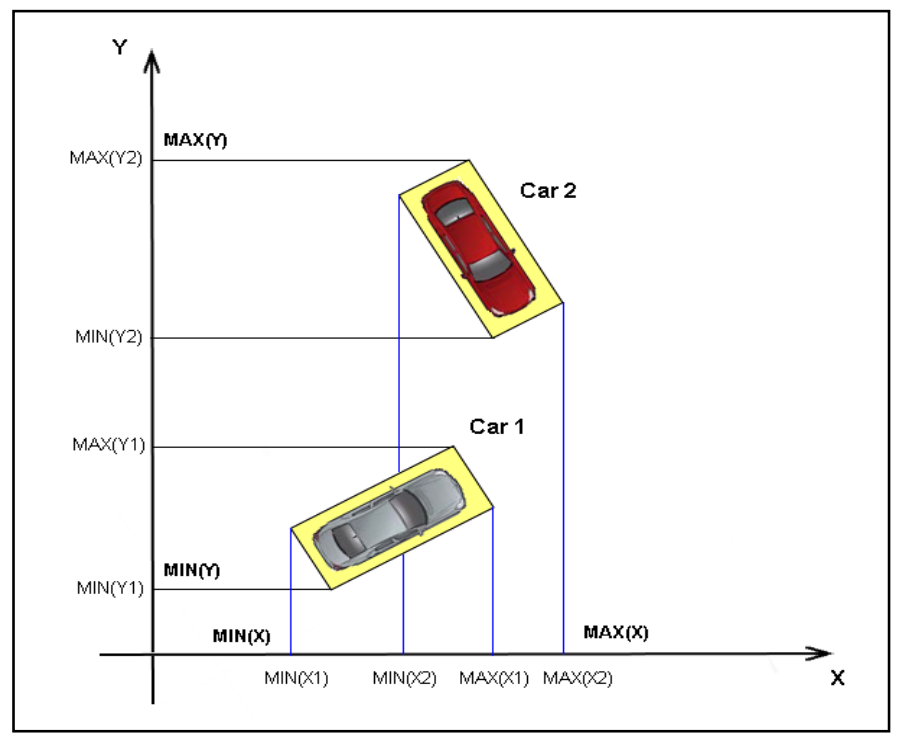

Fig. 2. Coordinates of the vehicles' limiting points.

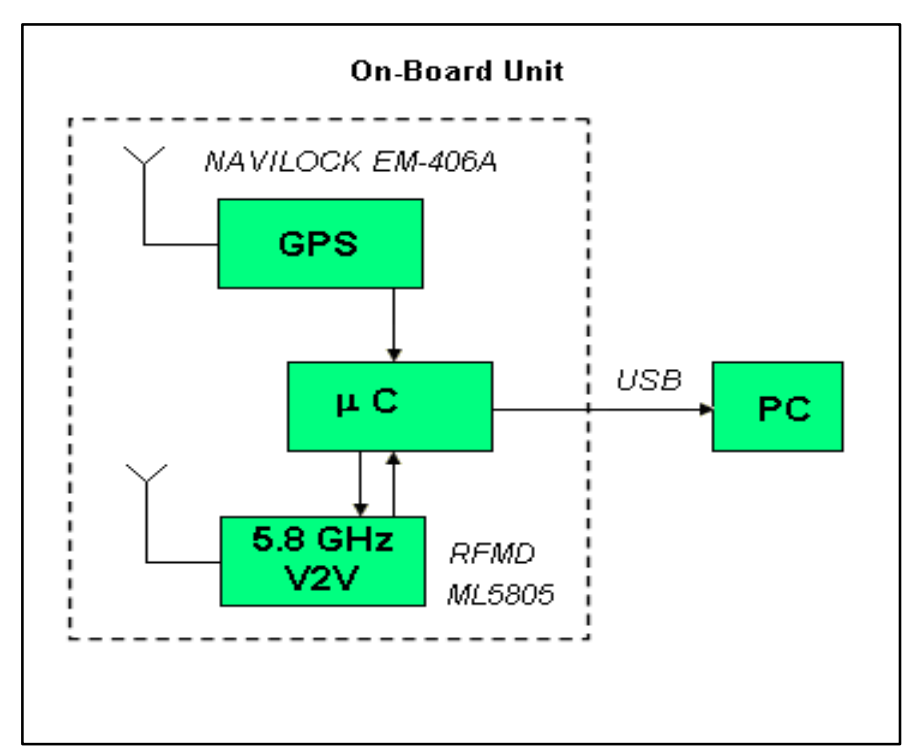

Fig. 3. Vehicle equipment's structural scheme.

The transmit power of the transmitter is $+21 \mathrm{dBm}$, and the receiver sensitivity is as good as that, namely, $-97 \mathrm{dBm}$ [8]. Data transmission is carried out in the broadcast mode. Controller $\mu \mathrm{C} 1$ provides for data collection from the GPS receiver, data receipt and transmission to the transceiver and data transmission to the $\mathrm{PC}$ or $\mathrm{CPU}$ for processing. Transformation of the coordinates, as received from the GPS receiver, from the WGS-84 system to the $\mathrm{X}-\mathrm{Y}$ plane coordinates, as well as implementation of the collision warning algorithm are carried out by means of a PC.

The received information is processed in real-time mode as a RMC command from a GPS receiver. The update rate of coordinates, speed and course angle is $1 \mathrm{~Hz}$. It should be noted, that for transmission of information about vehicle in terms of the SAE J2735 Standard, the so-called BSM (Basic Safety Message) can be used. This message is transmitted in a broadcast mode at the interval of $100 \mathrm{~ms}$. In addition to the information about the vehicle's location, the message contains data on the vehicle's speed, course angle north-up, status of the brake lights, overall sizes of the vehicle, etc.

\section{TESTS RESUlts}

The aim of the tests was to verify the operability of the collision warning system at an intersection under dynamic conditions at low speeds (up to $30 \mathrm{~km} / \mathrm{h}$ ). The tests were performed at an unsignaled road intersection in the conditions of low-rise urban development. The motion trajectories and the initial coordinates of the vehicles are shown in Fig.4. The two vehicles were approaching a road intersection simultaneously.

In case of collision probability, the driver of the first vehicle received a warning signal and the recommended safe speed value. According to the Road Traffic Rules, braking is the basic action to avoid a dangerous situation. Speed reduction to the recommended level (or lower) enables safe passage of an intersection. 


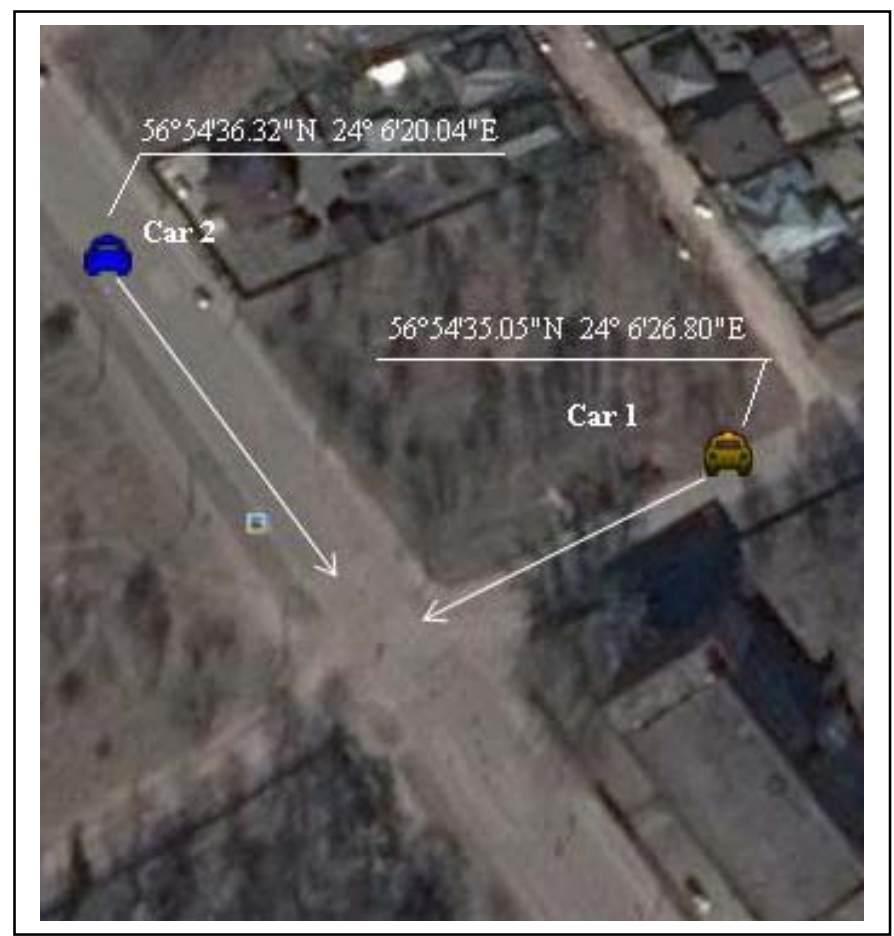

Fig. 4. The motion trajectories and the initial coordinates of the vehicles.

The results of the performed tests are shown in Table 1.

TABLE I. TESTS RESUlts

\begin{tabular}{|c|c|c|c|}
\hline $\begin{array}{c}\text { Test } \\
\mathbf{N r}\end{array}$ & $\mathbf{v}, \mathbf{k m} / \mathbf{h}$ & $\mathbf{D}, \mathbf{m}$ & $\mathbf{D}$ min, $\mathbf{m}$ \\
\hline 1 & 31 & 57 & 3 \\
\hline 2 & 24 & 62 & 2 \\
\hline 3 & 26 & 61 & 3 \\
\hline 4 & 22 & 54 & 1 \\
\hline
\end{tabular}

where $\mathrm{v}$ - the first vehicle's speed at the moment of receipt of a warning signal; $\mathrm{D}$ - real distance between the vehicles; $\mathrm{D}_{\min }-$ the predicted minimal distance between the vehicles (in the given case, between the installation points of the GPS receiver antennas).

The graphs showing the time dependencies of the vehicles' speeds are given in Fig.5. Besides, the first vehicle's speed graph indicates the moment of the warning message arrival.

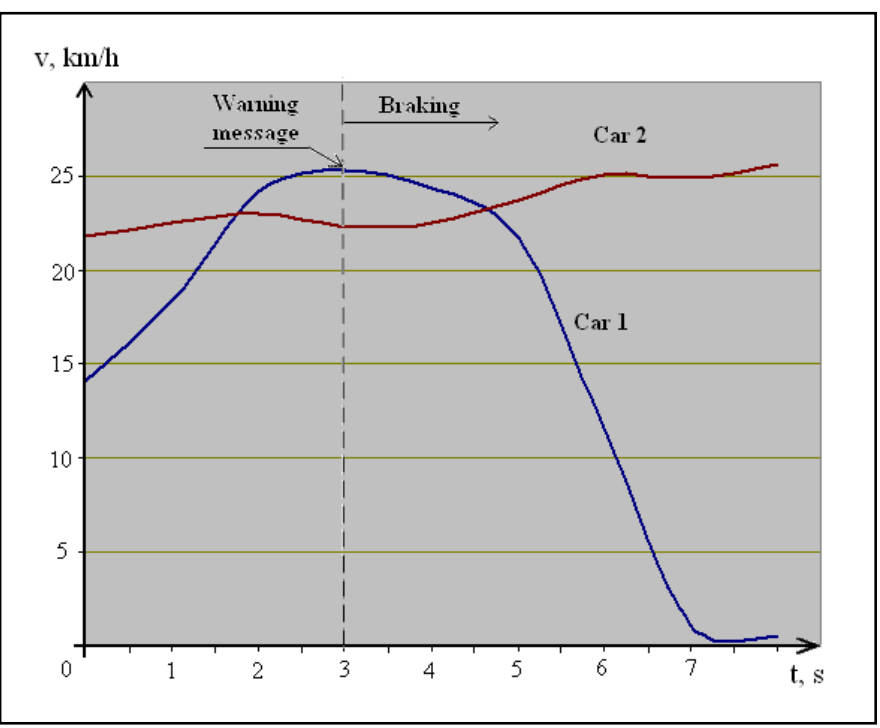

Fig. 5. Time dependencies of the vehicles' speeds.

The predicted time dependencies of the Sx and Sy functions, which served as a basis of forming a collision warning signal, are shown on the graphs in Fig.6.

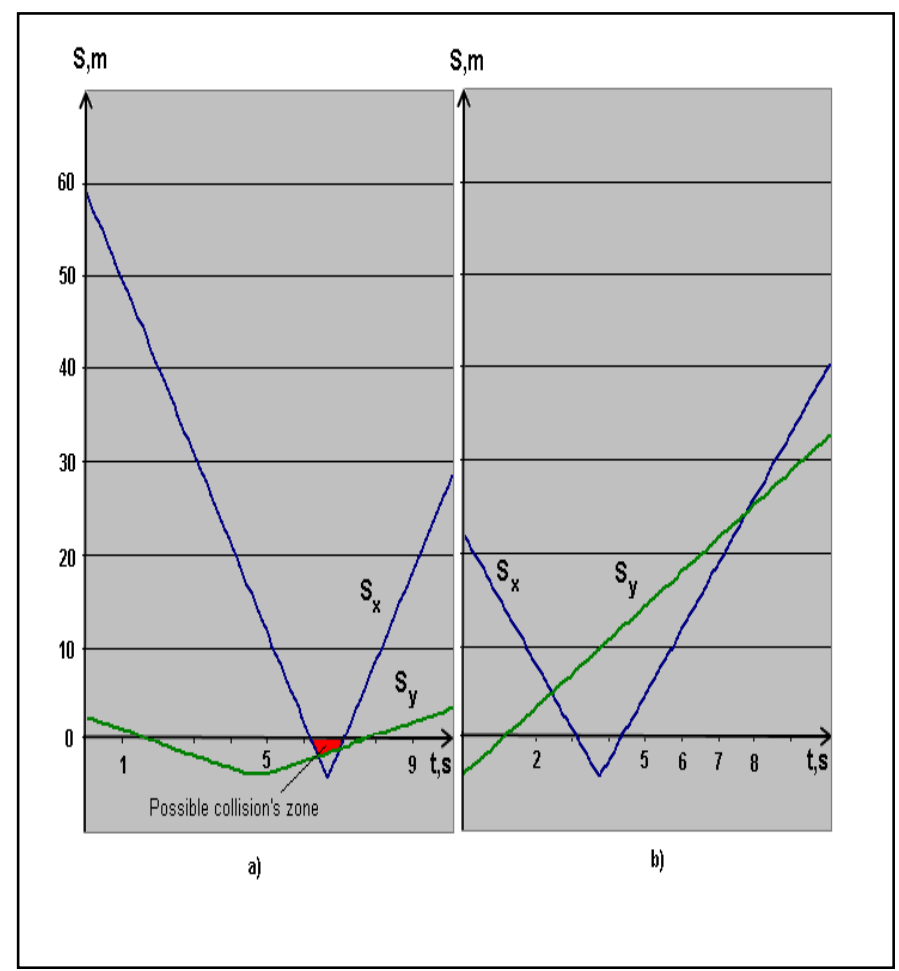

Fig. 6. The predicted time dependencies of the $S_{x}$ and $S_{y}$ functions: a) warning ; b) braking. 


\section{CONCLUSION}

The performed tests have revealed the possibility of using $\mathrm{V} 2 \mathrm{~V}$ communication based collision warning algorithm for unsignaled intersections. Broadcast transmission mode, as well as problems with the spread of radio in urban areas, greatly reduces the distance between vehicles in which the information exchange is possible. As a result, a warning signal comes rather late, which significantly reduces the potential for deceleration time.

Further studies in this direction foresee performance of tests with cars passing a road intersection directly or with turns from the stop position, as well as increasing the number of test subjects in order to validate the possibility of multichannel data receipt and processing.

\section{REFERENCES}

[1] "DSRC Implementation Guide. A Guide to Users of SAE J2735 Message Sets over DSRC," SAE International, 2010.

[2] F. Basma, Y. Tachwali, H. H. Refai,"Intersection Collision Avoidance System Using Infrastructure Communication,"14th International IEEE Conference on Intelligent Transportation Systems, Washington, USA, October 5-7, 2011.

[3] J. Ahrems, "Algorithm for determination of safety intersections," In Proc. 13th Biennial Baltic Electronics Conference (BEC2012), Tallinn, Estonia, pp. 175-178, 2012.

[4] J. Ahrems, "Appraisal of Feasibility of Using Vehicle-To-Vehicle Communications for Safe Passage of Unsignalled Road Intersection under Varying Conditions," IFAC Proceedings Volumes (IFACPapersOnline). Vol.12, Part 1,pp. 84-89, 2013.

[5] M. Brannstrom, J. Sjoberg, L. Helgesson, M. Christiansson, "A Realtime Implementation of an Intersection Collision Avoidance System", Preprints of the 18th IFAC World Congress, Milano, Italy, pp. 97949798, 2011

[6] J. Ahrems, "Collision Warning Algorithm for Passage of an Uncontrolled Road Intersection," In Proc. 14th Biennial Baltic Electronics Conference (BEC2014), Tallinn, Estonia, pp. 49-52, 2014.

[7] "NMEA 0183 Standard for Interfacing Marine Electronics Devices, Revision 3.01," NMEA Standard 0183, 2000.

[8] “RF Microdevice Data Manual,” RFMD Inc., 2008.

This is a post-print of a paper published in Proceedings of 25th International Conference "Radioelektronika 2015"

[http://dx.doi.org/10.1109/RADIOELEK.2015.7128978] and is subject to IEEE copyright. 